\title{
Heart-lung transplantation in a patient with large aortopulmonary collaterals by means of an extended approach
}

\author{
Klaus Kallenbach, MD, Andre R. Simon, MD, Axel Haverich, MD, and Martin Strüber, MD, Hannover, Germany
}

$\mathrm{F}$ or combined heart-lung transplantation, median sternotomy represents the standard approach, allowing exposure of the ascending aorta, both caval veins, and the distal trachea. ${ }^{1}$ However, aortopulmonary collaterals at the dorsal aspect of pulmonary vessels cannot be reached. Here we report of an innovative approach combined with atypical cannulation for cardiopulmonary bypass (CPB) to control severe aortopulmonary collaterals in a patient requiring combined heart-lung transplantation after multiple congenital heart operations.

\section{Clinical Summary}

A 25-year-old female patient presented with congestive heart failure of New York Heart Association class IV, vertigo, and central cyanosis. She was born with atresia of the pulmonary artery, a high ventricle septal defect, and multiple aortopulmonary collaterals, and she was operated on several times for re-establishment of pulmonary circulation: placement of a right-sited modified Blalock-Taussig shunt and unifocal attachment of a bronchial collat-

From the Department of Thoracic and Cardiovascular Surgery, Hannover Medical School, Hannover, Germany.

Received for publication Jan 12, 2007; accepted for publication Jan 23, 2007

Address for reprints: Klaus Kallenbach, MD, University Hospital Heidelberg, Department of Cardiac Surgery, INF 110, D-69120 Heidelberg, Germany (E-mail: klaus.kallenbach@med.uni-heidelberg.de).

J Thorac Cardiovasc Surg 2007;134:543-4

$0022-5223 / \$ 32.00$

Copyright (C) 2007 by The American Association for Thoracic Surgery doi:10.1016/j.jtcvs.2007.02.039 eral vessel, resection of the infundibulum, and connection of the right ventricle to the pulmonary artery combined with closure of a ventricular septal defect and placement of a Blalock-Taussig shunt. Postoperative arterial pulmonary hypertension required reopening of the ventricular septal defect and banding of the homograft. However, arterial pulmonary hypertension persisted and finally led to Eisenmenger's reaction combined with persistent aortopulmonary collaterals perfusing both the left and right pulmonary arteries (Figure 1). Because of rapid clinical deterioration but absence of alternate therapeutic options, the young patient was listed for high-urgency combined heart-lung transplantation.

After allocation of a suitable organ, the patient was prepared for transplantation. The chest was opened by using a clamshell incision. The ascending aorta, aortic arch, proximal descending aorta, and hilus of the left lung were prepared. Normothermic CPB was established by means of cannulation of the ascending aorta and percutaneous insertion of a long cannula reaching the right atrium (Heartport) through the left femoral vein. Then, a second aortic cannula was inserted into the distal descending aorta and connected to $\mathrm{CPB}$, and the patient was cooled to $26^{\circ} \mathrm{C}$. When the heart started to fibrillate, the aorta was clamped beneath the left subclavian artery and also directly above the distal cannulation. After left-sided pneumonectomy, several aortopulmonary collaterals of 5 to $8 \mathrm{~mm}$ connecting the clamped aorta and both pulmonary arteries were isolated and ligated. Aortic clamps were opened, and rewarming was initiated. Meanwhile, right pneumonectomy after mobilization of severe adhesions was undertaken. Thereafter, mobilization of the heart was commenced. Serious adhesions fixed the massively enlarged heart at its dorsal aspect, which was not reachable by using the clamshell approach. Therefore a partial caudal
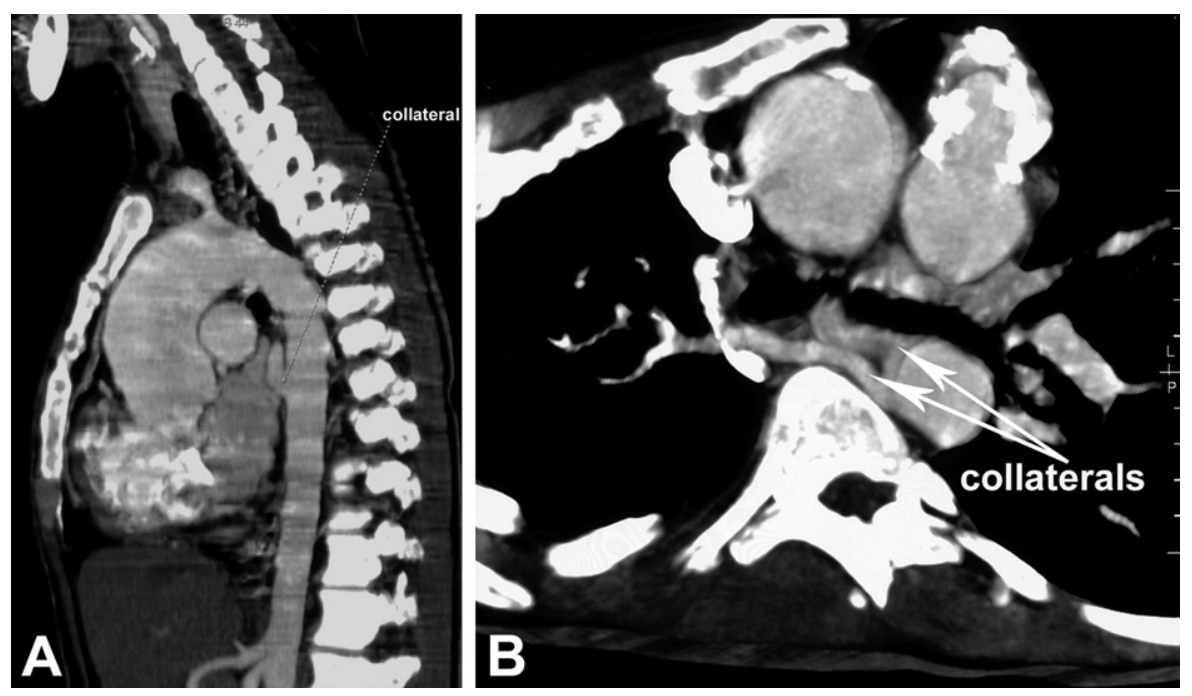

Figure 1. Demonstration of large aortopulmonary collateral before combined heart-lung transplantation. A computed tomographic scan identifies large collaterals, with its origin from the middle portion of the descending aorta to both lungs. 


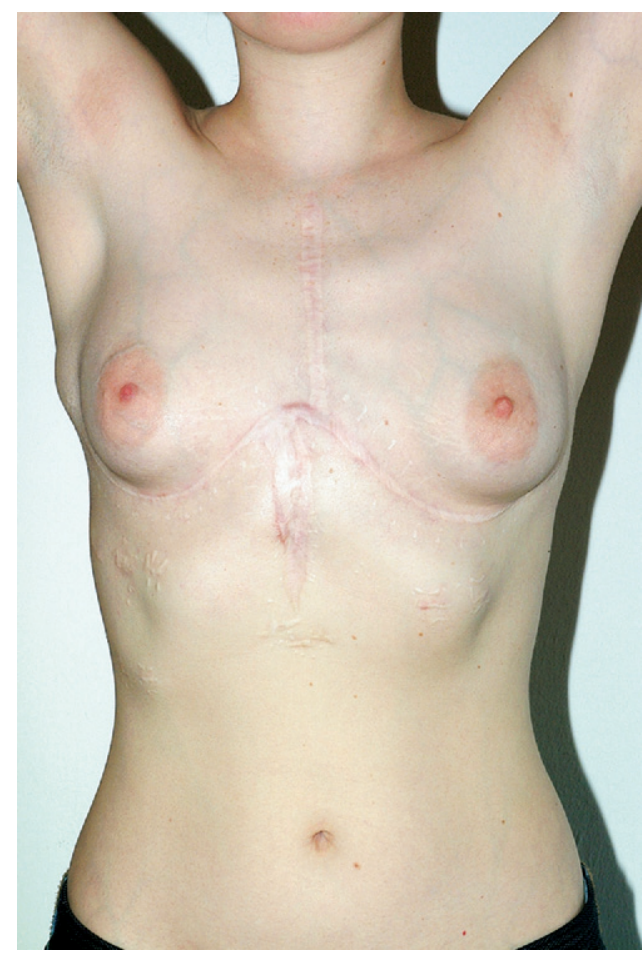

Figure 2. Photograph of the patient's frontal aspect 2 years postoperatively. The scar from an upper median sternotomy above the clamshell incision remains from congenital heart surgery during childhood.

median sternotomy reaching from the transverse sternotomy to the xiphoid was conducted. By using this approach, all aspects of the heart were accessible. The ascending aorta was clamped, and the heart was excised. The trachea was shortened and prepared for anastomosis with the graft. Both phrenic nerves were preserved in cuffs. Before orthotopic implantation of the graft, the distal aortic cannula was removed, and CPB was continued through the cannula in the ascending aorta. The operation was continued in a standard fashion by anastomosing the trachea, aorta, and caval veins. After careful deairing, blood flow was revived, and the heart started beating in sinus rhythm after adequate reperfusion. Weaning from $\mathrm{CPB}$ was undertaken without problems. Both transverse and median sternotomies were readapted with sternal wires, and the thoracotomy was closed in a routine fashion.

Postoperatively, 2 rethoracotomies were required because of bleeding. Otherwise, the postoperative course was uneventful.
Today, the patient is doing well and runs a business on an island. The incisions healed without complications but with excessive scar tissue, and the thorax is stabile (Figure 2).

\section{Discussion}

Median sternotomy represents the standard approach for combined heart-lung transplantation, allowing excellent access to the upper and anterior mediastinum. ${ }^{1}$ However, a clamshell incision allows more extensive access to lung hili and dorsal mediastinum. ${ }^{2,3}$ Marta and colleagues ${ }^{4}$ reported an inverse $\mathrm{T}$ incision, combining a clamshell incision with a partial proximal median sternotomy for access to anterior, supra-aortic, and lateral mediastinal structures. However, the remaining caudal sternum makes access to the posterior and caudal aspects of the heart difficult. To allow mobilization and luxation of the severely adhered heart, we added a partial distal median sternotomy to the clamshell incision.

The combination of both incisions has not been reported previously. It allows excellent exposure to all relevant structures that must be dissected for heart-lung transplantation as a redo case but leaves the upper sternum intact. Possible injury of mediastinal structures during resternotomy can be avoided, and postoperative stability of the thorax with intact upper mediastinum will quicken recovery.

In anticipation of aortopulmonary collaterals, we chose the clamshell incision initially. With use of double cannulation for exclusion of the descending aorta from perfusion and establishment of hypothermia, we safely controlled the collaterals. This cannulation technique has not been described yet for controlling severe aortopulmonary collaterals during heart-lung transplantation but was the pivotal strategy to conduct the operation successfully. With increasing numbers of adults requiring heart-lung transplantation after correction of congenital heart disease but eventually development of Eisenmenger's reaction, ${ }^{5}$ our approach might help to reduce the operative risk.

\section{References}

1. Harringer W, Haverich A. Heart and heart-lung transplantation: standards and improvements. World J Surg. 2002;26:218-25.

2. Macchiarini P, Ladurie FL, Cerrina J, Fadel E, Chapelier A, Dartevelle P. Clamshell or sternotomy for double lung or heart-lung transplantation? Eur J Cardiothorac Surg. 1999;15:333-9.

3. Kaiser LR, Pasque MK, Trulock EP, Low DE, Dresler CM, Cooper JD. Bilateral sequential lung transplantation: the procedure of choice for double-lung replacement. Ann Thorac Surg. 1991;52:438-45.

4. Marta GM, Aigner C, Klepetko W. Inverse T incision provides improved accessibility to the upper mediastinum. $J$ Thorac Cardiovasc Surg. 2005;129:221-3.

5. Hosseinpour AR, Cullen S, Tsang VT. Transplantation for adults with congenital heart disease. Eur J Cardiothorac Surg. 2006;30:508-14. 